\title{
SUR L'INEGALITE D'ACIDITE DES DEUX FACES D'UN FROMAGE (1)
}

\author{
par M. MESNIL
}

Les deux faces d'un fromage à pâte molle n'ont pas la même acidité et cette différence très sensible étant de nature à faire modifier la fahrication, il nous a paru intéressant de l'étudier.

Nous avons en effet très fréquemment constaté que la moisissure (penicillium)qui pousse sur les fromages et dont le rôle est de retirer l'acidité de la pâte, de préparer le terrain aux feıments du rouge et de rendre ainsi le milieu neutre ou légèrement alcalin n'a pas toujours le même développement. Cette moisissure est différente d'interısité suivant qu'on observe l'une ou l'autre des deux faces.

Sur l'une, dite du premier salage, le penicillium est toujours plus vigoureux, pousse plus vite et rccouvre très rapidement en entier toute la surfare du fromage en formant un léger duvet continu; sur l'autre face au contraire, ce même penicillium est toujours moins abondant, moins vigoureux et ne recouvre pas toujours en entier toute la surface du fromag 3 .

Si nous désignons par $\mathrm{A}$ la première face et par $\mathrm{B}$ la deuxième, nous remarquons que la face $A$ est cello qui depuis le début de la fabrication est exposée dans le moule le plus longtemps à l'air et à l'humidité. Le caillé prélevé dans la base d'emprésurage remplit d'abord le moule en entier, puis, descend lentement en diminuant de volume et en se débarrassant du sérum qui s'écoule sur les claies. Ce n'est que le lendemain de la fabrication que le fromage est retourné, et cette face A qui était exposée à l'air depuis la mise en moule repose maintenant sur la claie où le sérum coule abondamment, constituant ainsi pour cette fase un miiieu essentiellement acide dont elle s'imprègne. Ce même jour, quelques heures plus tard, le fromage est de nouveau retourné et cette face est encore exposée à l'air humide et chaud de la salie; après salage, elle restera ainsi jusqu'au surlendemain de la fabrication. Il résulte done de ces manipulations que la face $A$ est plus longtemys que l'autre en contact direct avec une atmosphère saturće d'bumidité et l'on pourrait dire d'acidité, car c'est la période de la fabrication où la fermentation Jactique est ıa plus intense (acidité du lait, acidité du caillé, acidité du sérum).

Les analyses n'ont fait que confirmer ces observations. Nous avons prélevé dans une série de fromages de camembert du même âge des échantillons de $\mathrm{A}$ et $\mathrm{B}$ et nous avons toujours constaté que l'acidité de la face A était supérieure à celle de la face B. Cette acidité, faible au début, va en augmentant rapidement à partir du cinquième jour

(1) Ce travail d'un vif intérêt pratique a été présenté par M. Lindet à l'Académie d'Agriculture le 16 juin dernier. Nous prenons plaisir à le donner iei. (R.) 
de la fabrication, croît encore au' séchnir pour diminuer ensuite au fur et à mesure que le fromage vieillit et devient alcalin : ce qui du reste est logique et a été déjà constaté.

Cette inégalité d'acidité a une répercussion très sensible sur le développement du penicillinm qui, on le sait, pousse avec d'autant plus de facilité et de rapidité que le milieu est plus acide; l'expérience prouve en effet que si c'est entre le dixième et le quinzième jour de la fabrication que l'acidité des deux faces est la plus forte, c'est aussi entre le dixième et le quinzième jour que le penicillium atteint son maximum de développement. Or, en raison de cette relation étroite; il y a un intérêt pour la fabrication à équilibrer autant que possible le développement de la moisissure pour en rendre la croissance uniforme sur les deux faces.

Il appartiendra donc aux fromagers de rechercher cet équilibre:

$1^{0}$ En retournant le plus tôt possible le fromage dans le moule, ce qui activera la sortie de sérum.

$2^{\circ}$ En chauffant régulièrement jour et nuit la salle de fabrication au-dessus de $20^{\circ}$ pour que l'égouttage se fasse rapidement. De ce faít le petit-lait restera moins longtemps $\in \mathrm{n}$ contact avec le fromage. $\mathrm{Ce}$ dernier point est important, car le plus souvent, la nuit, la tempérade la laiterie descend parfois au-dessous de $12^{\circ}$, le sérum s'égoutte mal alors et reste emprisonné dans la pâte où il fermente et cause des accidents de fabrication.

$3^{\text {o }}$ En se rappelant enfin que l'égouttage est le point le plus délicat de la fabrication. Un fromage mal égoutté sera toujours un fromage de quasité médiocre, quelle que soit la qualité du lait.

En surveillant done avec soin la fabrication, l'égouttage sera régulier sur les deux faces; la fermentation lastique aura la même intensité et, par suite, l'acidité ne présentera plus d'aussi grands écarts toujours préjudiciables à la maturation des fromages; le développement du penicillium sera semblable sur les deux faces et, le terrain étant bien préparé, l'affinage se fera normalement à la cave.

\section{BIBLIOGRAPHIE ANALYTIQUE}

\section{LES LIVRES}

\section{Patriat R. - L'élevage dans le département de la Meuse.} Th. Doct. Vét. Paris, 1926.

Jusqu'en 19c0, la porulation kovine du défartement de la Meuse a été très mélangée, far suite de l'introduction, corrme éléments améliorateurs, de taureaux de races très diverses : Schwytz, frikourgeois, kernois, montkéliard, durhams, hollandais, flemands et méme normands. De 1505 à 1914, des eflorts furent faits pour uniformiser le troupeau, et, depuis la guerre, la même tendance s'est accentuée. 